\title{
Clozapine Alters Sleep-Wake Behavior in Rats
}

\author{
Silke Sorge', Thomas Pollmächer*,' and Marike Lancel' \\ 'Max Planck Institute of Psychiatry, Munich, Germany
}

\begin{abstract}
Clozapine is an atypical antipsychotic agent showing therapeutic efficacy superior to that of classical neuroleptics. Clozapine has strong sedative effects, but detailed studies on the drug influencing sleep in rodents are lacking. We studied the effects of clozapine on sleep and body temperature in rats. Clozapine $(0,2.5$, and $7.5 \mathrm{mg} / \mathrm{kg}$ ) was given i.p. to male Wistar rats at the beginning of the rest period. After administration of $7.5 \mathrm{mg} / \mathrm{kg}$ clozapine, animals were significantly more awake during the first $2 \mathrm{~h}$ postinjection. In parallel, the slow-wave activity (SWA) was suppressed. In the following $2 \mathrm{~h}$ non-REM sleep was markedly increased, whereas the SWA returned to baseline. At both doses clozapine decreased overall wakefulness and increased non-REM sleep on the first treatment day, which was associated with prolonged non-REM sleep episodes. These effects were transiently present even after subchronic treatment ( 7 days). After acute treatment, $7.5 \mathrm{mg} / \mathrm{kg}$ clozapine significantly reduced REM sleep and pre-REM sleep due to an increase in REM sleep latency and a reduction in the number of REM sleep episodes. Furthermore, clozapine produced a transient decrease in brain temperature that was followed by a moderate, but long-lasting elevation. To conclude, clozapine affected sleep-wake behavior in a way comparable to its effects in humans, suggesting that the rat is a suitable model for further studies on the underlying mechanisms.

Neuropsychopharmacology (2004) 29, | 462-1469, advance online publication, 7 April 2004; doi: 10.1 038/s.npp. 1300445
\end{abstract}

Keywords: clozapine; sleep; rat; temperature; EEG signals; slow-wave activity

\section{INTRODUCTION}

Clozapine is an outstanding antipsychotic drug with unique properties. It is effective in treatment-refractory patients and against negative symptoms, whereas it lacks side effects that are typical for classical neuroleptics (Baldessarini and Frankenburg, 1991). Its therapeutic advantages are, however, counterbalanced by a variety of unusual side effects. Besides life-threatening agranulocytosis, the most important side effects are a prominent weight gain and sedation. During the day patients complain about sleepiness, but night sleep is also affected. Polysomnographic studies performed during the treatment of schizophrenic patients with clozapine consistently showed that clozapine improves sleep efficiency and increases non-REM sleep, particularly stage 2 sleep (Wetter et al, 1996; Hinze-Selch et al, 1997; Lee et al, 2001). Some studies found also a suppressive effect of clozapine on slow-wave sleep (SWS) of healthy men and patients (Touyz et al, 1977; Hinze-Selch et al, 1997).

The mechanisms underlying the effects and side effects of clozapine are unknown. An interpretation of the data is difficult because of an extensive affinity of clozapine

\footnotetext{
* Correspondence: T Pollmächer, Max Planck Institute of Psychiatry, Kraepelinstr. 10, Munich 80804, Germany, Tel: + 4989 30622572, Fax: + 4989 30622562, E-mail: topo@mpipsykl.mpg.de

Received 7 July 2003; revised I 5 December 2003; accepted 2 February 2004

Online publication: 27 February 2004 at http://www.acnp.org/citations/ Npp02270403303/default.pdf
}

to various neurotransmitter receptors, such as dopamine, serotonine, histamine, acetylcholin, and noradrenaline receptors (Pollmächer, 2002). The blockade of serotonine $5 \mathrm{HT}_{2}$ receptors (Wilkinson and Dourish, 1991; Stutzmann et al, 1992) or histamine $\mathrm{H}_{1}$ receptors (Lin et al, 1994) might be involved in clozapine's effects on sleep-wake behavior, but also immunmodulatory properties may play a role. It has been shown that treatment with clozapine has numerous effects on the immune system including the induction of transient fever and an increased production of inflammatory cytokines such as tumor necrosis factor (TNF)- $\alpha$ (Pollmächer et al, 1996; Hinze-Selch et al, 2000), which was shown to have somnogenic properties in rats (Krueger et al, 2001).

In rats, clozapine reportedly promotes non-REM sleep and suppresses REM sleep (Spierings et al, 1977; Ongini et al, 1993). However, there is no study that analyzed shortand long-time effects of clozapine on sleep-wake behavior after acute and subchronic treatment. In the present study we investigated the influence of clozapine on sleep-wake patterns, slow-wave activity (SWA) in the electroencephalogram (EEG) during non-REM sleep and brain temperature in rats on the first, third, and seventh day of treatment with clozapine. To keep the results comparable to the observations in humans, we chose the rest period of rats for investigation. Long-time measurements of EEG activity during the entire rest period ensured the registration of immediate and recovery effects of clozapine on sleep-wake behavior. 


\section{METHODS}

\section{Animals}

The experimental design was approved by the Ethical Committee on Animal Care and Use of the Government of Bavaria, Germany. Adult male Wistar rats, purchased from Charles River (Sulzfeld, Germany), were housed in groups of two to three per cage in a ventilated, sound-attenuated Faraday room under a $12-\mathrm{h}$ light/12-h dark schedule (50-80 lux) at an ambient temperature of $20-22^{\circ} \mathrm{C}$. Food and water were available ad libitum. The animals were handled daily.

\section{Drug}

Clozapine was used in the form of the commercially available Leponex ${ }^{\circledR}$ solution for injections (Novartis Pharma, Nuremberg, Germany). The solvent of clozapine, which consists of the ingredients of the solution for injections, served as a vehicle. Ingredients and recipe for the solvent were kindly provided by Novartis.

\section{Assessment of Sleep-Wake Behavior and Brain Temperature}

Under deep inhalation isoflurane anesthesia, 24 rats weighing 190-220 g at the time of surgery were chronically implanted with EEG and electromyogram (EMG) electrodes, and a thermistor for recording brain temperature (Tbr) as described previously (Lancel et al, 1995). In total, 5 weeks were allowed for recovery from surgery and at least 4 days to adapt to the recording conditions. During this time the animals were housed individually.

The experiment lasted nine consecutive days. On every experimental day an intraperitoneal (i.p.) injection was given at the beginning of the light period. On the first day all animals received pyrogen-free saline and on the second day vehicle (baseline recordings). On the following 7 days, rats were injected with either vehicle, $2.5 \mathrm{mg} / \mathrm{kg}$ clozapine, or $7.5 \mathrm{mg} / \mathrm{kg}$ clozapine ( $n=8$ each). EEG, EMG, and brain temperature were recorded during the entire 12-h light period on both baseline days and on the first, third, and seventh day of treatment.

EEG and EMG were amplified and filtered (EEG: high pass $0.3 \mathrm{~Hz}$, low pass $29 \mathrm{~Hz}, 48 \mathrm{~dB}$ /octave; EMG: high pass $16 \mathrm{~Hz}$, low pass $3000 \mathrm{~Hz}, 6 \mathrm{~dB} /$ octave). The EEG, rectified and integrated EMG, and Tbr were digitized at a sampling rate of $64 \mathrm{~Hz}$. The EEG signal was subjected to a spectral analysis and a power spectrum was computed in the frequency range of $1-4 \mathrm{~Hz}(0.5-\mathrm{Hz}$ bins $)$ in $2-\mathrm{s}$ windows. Power densities were averaged to calculate SWA. SWA and Tbr values were averaged over 10-s epochs.

An off-line program displayed EEG and EMG signals of 10-s epochs on the screen for manual scoring of the vigilance states wakefulness, non-REM sleep, pre-REM sleep, and REM sleep (scoring criteria of Neckelmann and Ursin, 1993; non-REM sleep = SWS-1 + SWS-2, pre-REM sleep $=$ transition-type sleep).

For each 12-h recording period, the total number and average duration of non-REM sleep and REM sleep episodes were determined. Latency to non-REM sleep was arbitrarily defined as the 20th epoch of non-REM sleep and latency to
REM sleep as the third epoch of REM sleep (Lancel et al, 1996). For each 2-h interval, total time spent in each vigilance state, average SWA within non-REM sleep, and average Tbr were computed. For standardization, all sleep parameters were expressed as percentage of the group mean of the entire vehicle recording period. Thereafter, SWA was log transformed. For each animal Tbr was expressed as deviation from the vehicle mean.

For statistical evaluation, data were submitted to a twoway repeated-measures analysis of variance (ANOVA, Greenhouse-Geisser correction), with treatment (three levels: vehicle, 2.5 , or $7.5 \mathrm{mg} / \mathrm{kg}$ clozapine) as the betweensubjects factor and time (six levels) as the within-subjects factor. If appropriate, ANOVAs were followed by tests using contrasts (Tukey test).

As no significant differences were found between treatment with saline and vehicle, only the vehicle data were used (saline data are not shown).

\section{RESULTS}

\section{Effect of Clozapine on Sleep-Wake Behavior and Brain Temperature}

Vigilance states. Time spent in each vigilance state as well as the ANOVA results are presented in Table 1. Figure 1 shows the time course of vigilance states during the vehicle day, and the first, third, and seventh day of treatment. As to be seen in Table 1, on the first treatment day there was an effect of ANOVA following group by time in wakefulness. Tukey test showed that the animals of the $7.5 \mathrm{mg} / \mathrm{kg}$ clozapine group were significantly more awake than the animals of the vehicle group as well as the animals of the $2.5 \mathrm{mg} / \mathrm{kg}$ clozapine group during the first $2 \mathrm{~h}$ postinjection (Figure 1). During hours 3-4 both clozapine-treated groups spent significantly less time awake than the vehicle group. No significant differences in the amount of wakefulness became apparent on the third treatment day. On the seventh treatment day wakefulness was temporarily decreased by both doses of clozapine in the hours $3-4$ and by $2.5 \mathrm{mg} / \mathrm{kg}$ clozapine also in the hours 7-8 following treatment.

Concomitant to the changes in waking, non-REM sleep was markedly suppressed during the first 2-h interval after the first injection of $7.5 \mathrm{mg} / \mathrm{kg}$ clozapine. During the following $2 \mathrm{~h}$, non-REM sleep was increased by both doses of clozapine. No significant differences in the amount of non-REM sleep occurred on the third treatment day. On the seventh treatment day, clozapine dose-independently increased non-REM sleep during hours 3-4 and 7-8.

After acute treatment $2.5 \mathrm{mg} / \mathrm{kg}$ clozapine reduced preREM sleep during the first $2 \mathrm{~h}$, while the higher dose suppressed pre-REM as well as REM sleep during the first $4 \mathrm{~h}$, which was followed by an increase of REM sleep during hours 9-12. On the following treatment days, no significant differences in REM sleep and pre-REM sleep were observed.

SWA in the EEG within non-REM sleep. Figure 2 depicts the time course of SWA within non-REM sleep during the vehicle day and the first, third, and seventh day of treatment. The lower dose of clozapine did not affect SWA in the EEG within non-REM sleep. EEG-SWA was markedly attenuated during the first $2 \mathrm{~h}$ after acute and 
Table I Percentage of Time Spent in Wakefulness, Non-REM, Pre-REM, and REM Sleep After Administration of Vehicle, 2.5, and 7.5 mg/kg Clozapine

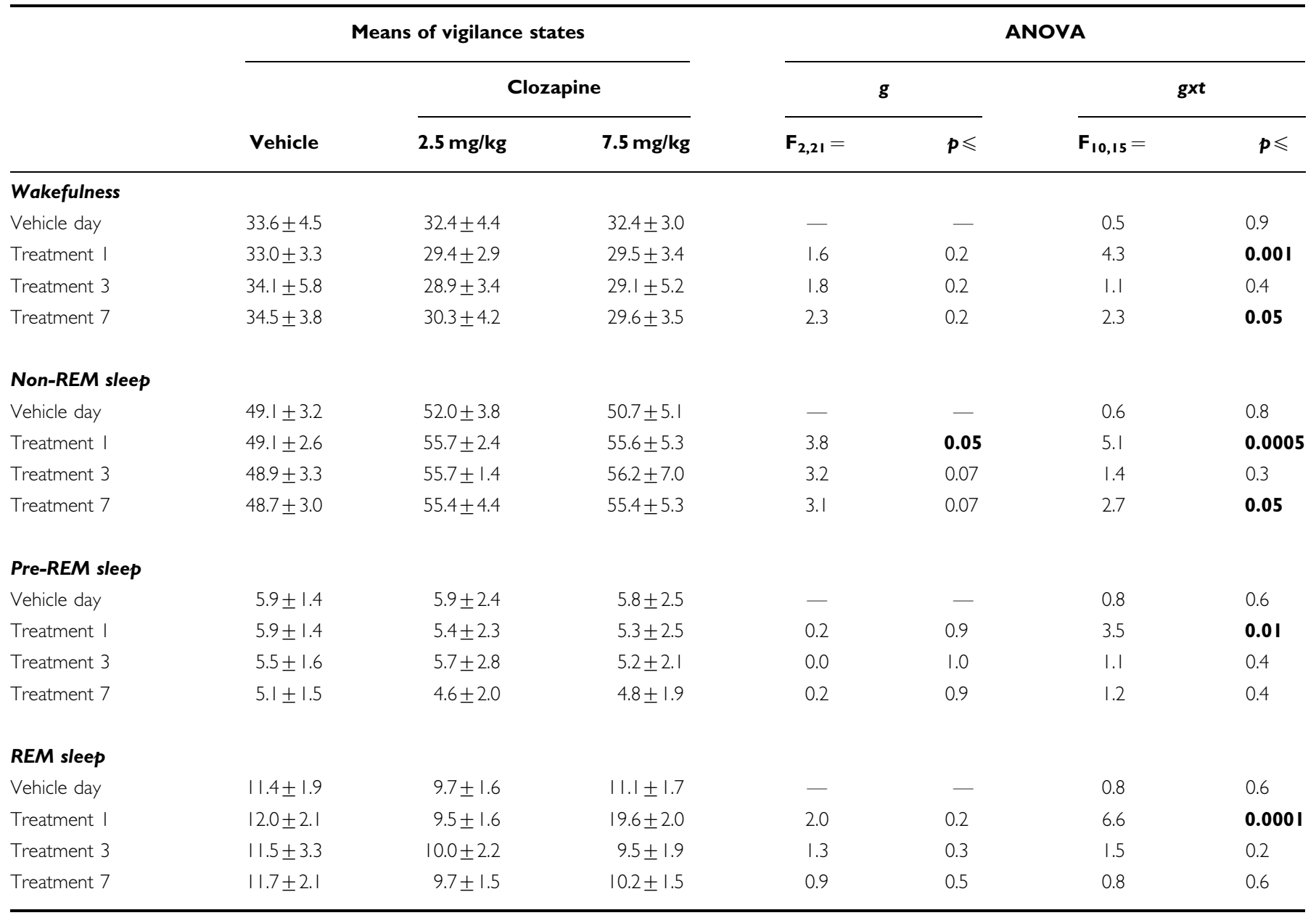

Values are means $\pm S D, n=8$. In the last columns, results of ANOVA are given. ANOVAs were performed on 2-h values standardized on group means of vehicle day. Significant differences are indicated by bold $p$-values. Effect of time was always significant and therefore not shown. $g$ group, gxt group by time.

third administration of $7.5 \mathrm{mg} / \mathrm{kg}$ clozapine. This effect was absent on treatment day 7 (for statistical details see legend of Figure 2).

Parameters of sleep structure. The means of non-REM and REM sleep latencies, the number and duration of non-REM, and REM sleep episodes, and the results of ANOVA are presented in Table 2. Figure 3 shows the temporal course of sleep architecture parameters over the experimental days.

Non-REM sleep onset was not significantly affected on any experimental day. The number of non-REM sleep episodes was reduced after the first administration of $7.5 \mathrm{mg} / \mathrm{kg}$ and after the third administration of $2.5 \mathrm{mg} / \mathrm{kg}$ clozapine. The duration of non-REM sleep episodes was prolonged by the high dose of clozapine during the entire course of the experiment and by the low dose on the third and seventh day of treatment.

REM sleep latency was increased after the first and third treatment with $7.5 \mathrm{mg} / \mathrm{kg}$ clozapine and after the seventh treatment with $2.5 \mathrm{mg} / \mathrm{kg}$ clozapine. On the first treatment day, the number of REM sleep episodes was decreased after administration of $7.5 \mathrm{mg} / \mathrm{kg}$ clozapine. The duration of REM sleep episodes was not affected at any time.
Observations on the EEG signal. In four out of eight animals receiving $2.5 \mathrm{mg} / \mathrm{kg}$ clozapine and six out of eight animals receiving $7.5 \mathrm{mg} / \mathrm{kg}$ clozapine striking alterations occurred in the EEG during wakefulness in particular in the first $4 \mathrm{~h}$ postinjection, whereas after vehicle administration the EEG remained unremarkable in all animals $\left(\chi^{2}(\mathrm{df}=2)=9.6 ; p \leqslant 0.01\right)$. These EEG signals were characterized by high amplitudes and spindle-like bursts, which were often accompanied by EMG signals compatible with myoclonic jerks (Figure 4). In parallel, animals showed an apathetic dozing behavior and twitches of the head. During the first $2 \mathrm{~h}$ postinjection time spent in this EEG defined state was on the first treatment day: $8 \pm 8.8 \%$, range $0-19.4 \%$; on the third treatment day: $2.9 \pm 3.5 \%$, range $0-7.6 \%$; on the seventh treatment day: $0.3 \pm 0.6 \%$, range $0-1.4 \%$ in the $7.5 \mathrm{mg} / \mathrm{kg}$ clozapine group. In the $2.5 \mathrm{mg} / \mathrm{kg}$ clozapine group the respective numbers were on the first treatment day: $2.2 \pm 4.1 \%$, range $0-9.4 \%$; on the third treatment day: $2 \pm 2.2 \%$, range $0-5.3 \%$; and on the seventh treatment day: $2 \pm 3.1 \%$, range $0-7.4 \%$.

Wistar rats often show trains of spike-wave patterns reminiscent of absence epilepsy in the EEG during wakefulness (Vergnes et al, 1982). On the vehicle day, three 

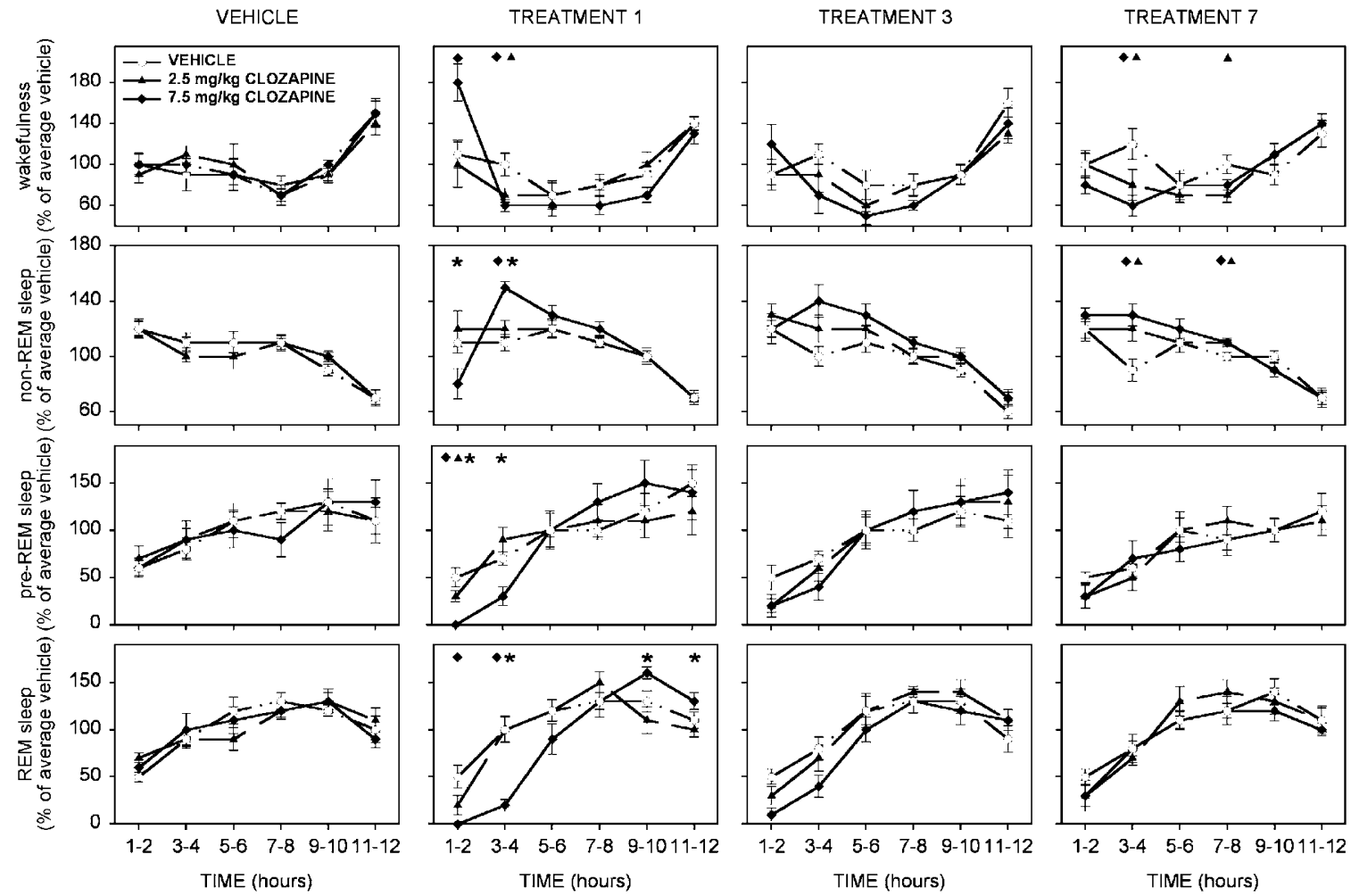

Figure I Time course of wakefulness, non-REM, pre-REM, and REM sleep after vehicle, 2.5, and $7.5 \mathrm{mg} / \mathrm{kg}$ clozapine on the vehicle day, the first, third, and seventh treatment day (means \pm SEM, $n=8$ ). The data are expressed as percentage of the 12 -h vehicle values. Significant differences between the vehicle and a clozapine group are indicated by the clozapine group symbol and differences between the clozapine groups by an asterisk at the top of the plots $(p \leqslant 0.05$, Tukey test).
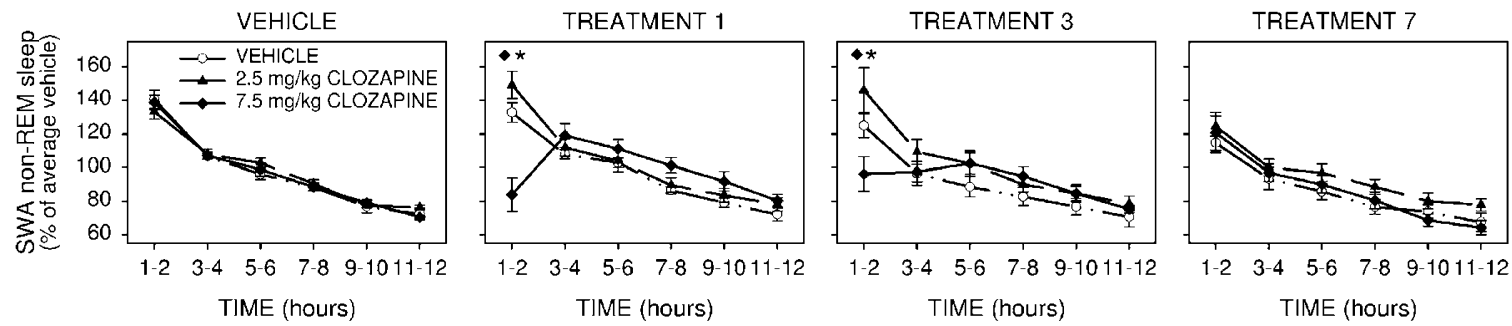

Figure 2 Time course of slow-wave activity in the EEG within non-REM sleep after vehicle, 2.5, and $7.5 \mathrm{mg} / \mathrm{kg}$ clozapine on the vehicle day, the first, third, and seventh treatment day (means $\pm \mathrm{SEM}, n=8$ ). Data are expressed as percentage of the 12-h vehicle values. Results of ANOVA follow group by time: Vehicle day: $F(\mid 0,105)=0.8, p \leqslant 0.6$; treatment day $I: F(|0| 05)=12.4,, p \leqslant 0.000 \mid$; treatment day $3: F(\mid 0,105)=5.8, p \leqslant 0.00 \mid$; treatment day 7 : $F(I 0,105)=1.2, p \leqslant 0.4$. Significant differences between the vehicle and a clozapine group are indicated by the clozapine group symbol and differences between the clozapine groups by an asterisk at the top of the plots ( $p \leqslant 0.05$, Tukey test).

out of eight animals of the vehicle group, five out of eight of the 2.5 , and four out of eight of the $7.5 \mathrm{mg} / \mathrm{kg}$ clozapine group exhibited this spike-wave pattern of absence epilepsy in the EEG. Clozapine appeared to induce and exacerbate spike-wave patterns during wakefulness. Video observations revealed that the rats showed the typical freezing and absence behavior of absence epilepsy during the assessment of these EEG signals. After treatment with clozapine, the frequency of spike-wave patterns was much higher, while it remained stable in the vehicle group. Furthermore, clozapine induced absence epilepsy in two animals that were free of spike-waves on the vehicle day, in one animal in the 2.5 and in another animal in the $7.5 \mathrm{mg} / \mathrm{kg}$ clozapine group (data not shown).
Brain temperature. The time course of $\mathrm{Tbr}$ is depicted in Figure 5. On all treatment days clozapine produced a transient, dose-dependent drop in brain temperature, whereas it elevated it during the second half of the light period (for statistical details see legend of Figure 5).

\section{DISCUSSION}

The present study was performed to investigate the effects of the atypical antipsychotic drug clozapine on the sleep-wake pattern in the rat. In agreement with previous findings (Spierings et al, 1977; Ongini et al, 1993), clozapine promoted non-REM sleep. The present study 
Table 2 Latencies to Non-REM and REM Sleep, Numbers, and Durations of Non-REM and REM Sleep Episode After Vehicle, 2.5, and $7.5 \mathrm{mg} / \mathrm{kg}$ Clozapine

\begin{tabular}{|c|c|c|c|c|c|}
\hline & \multicolumn{3}{|c|}{ Means } & \multirow{2}{*}{\multicolumn{2}{|c|}{$\frac{\text { ANOVA }}{\mathrm{g}}$}} \\
\hline & \multirow[b]{2}{*}{ Vehicle } & \multicolumn{2}{|c|}{ Clozapine } & & \\
\hline & & $2.5 \mathrm{mg} / \mathrm{kg}$ & $7.5 \mathrm{mg} / \mathrm{kg}$ & $\mathbf{F}_{2,21}=$ & $p \leqslant$ \\
\hline \multicolumn{6}{|l|}{ Vehicle day } \\
\hline \multicolumn{6}{|l|}{ Non-REM sleep } \\
\hline Latency (min) & 29.9 & 21.7 & 25.3 & - & - \\
\hline Number of episodes & 121 & 119 & 120 & - & - \\
\hline Duration of episodes (min) & 1.8 & 1.8 & 1.9 & - & - \\
\hline \multicolumn{6}{|l|}{ REM sleep } \\
\hline Latency (min) & 50.7 & 46.7 & 55.3 & - & - \\
\hline Number of episodes & 42 & 35 & 34 & - & - \\
\hline Duration of episodes (min) & 1.1 & 1.0 & 1.2 & - & - \\
\hline \multicolumn{6}{|l|}{ Treatment day I } \\
\hline \multicolumn{6}{|l|}{ Non-REM sleep } \\
\hline Latency (min) & 30.2 & 27.6 & 27 & 0.5 & 0.6 \\
\hline Number of episodes & 122 & 114 & 99 & 12.7 & 0.0002 \\
\hline Duration of episodes (min) & 1.7 & 2.1 & 2.5 & 12.8 & 0.0002 \\
\hline \multicolumn{6}{|l|}{ REM sleep } \\
\hline Latency (min) & 57.5 & 102.4 & 250.8 & 15.5 & 0.0001 \\
\hline Number of episodes & 39 & 32 & 24 & 9.7 & 0.001 \\
\hline Duration of episodes (min) & 1.2 & 1.1 & 1.4 & 2.6 & 0.1 \\
\hline \multicolumn{6}{|l|}{ Treatment day 3} \\
\hline \multicolumn{6}{|l|}{ Non-REM sleep } \\
\hline Latency (min) & 25.7 & 17.8 & 17.4 & 0.5 & 0.6 \\
\hline Number of episodes & 130 & 106 & 112 & 4.7 & 0.02 \\
\hline Duration of episodes (min) & 1.6 & 2.2 & 2.3 & 6.5 & 0.006 \\
\hline \multicolumn{6}{|l|}{ REM sleep } \\
\hline Latency (min) & 55.6 & 92.5 & 176.6 & 3.9 & 0.04 \\
\hline Number of episodes & 41 & 32 & 26 & 2.1 & 0.1 \\
\hline Duration of episodes ( $\mathrm{min}$ ) & 1.1 & 1.2 & 1.4 & 2.4 & 0.1 \\
\hline \multicolumn{6}{|l|}{ Treatment day 7} \\
\hline \multicolumn{6}{|l|}{ Non-REM sleep } \\
\hline Latency (min) & 19.1 & 21.9 & 21 & 1.4 & 0.3 \\
\hline Number of episodes & 123 & 107 & 115 & 2.9 & 0.08 \\
\hline Duration of episodes (min) & 1.7 & 2.3 & 2.2 & 8.6 & 0.002 \\
\hline \multicolumn{6}{|l|}{ REM sleep } \\
\hline Latency (min) & 57.7 & 126.7 & 95.2 & 3.3 & 0.05 \\
\hline Number of episodes & 40 & 30 & 30 & 0.5 & 0.6 \\
\hline Duration of episodes ( $\mathrm{min}$ ) & 1.1 & 1.2 & 1.3 & 1.7 & 0.2 \\
\hline
\end{tabular}

Values are mean, $n=8$. Last columns gives the results of ANOVA performed on values standardized on group means of vehicle day, significant differences are indicated by bold p-values. g group.

showed that the increase in the amount of non-REM sleep was accompanied by a reduction in the number and a pronounced increase in the duration of non-REM sleep episodes. This suggests that clozapine increases sleep maintenance in rats. Intriguingly, an improvement of sleep continuity is the most consistent finding with regard to sleep behavior in clozapine-treated patients (Hinze-Selch et al, 1997; Wetter et al, 1996; Lee et al, 2001). The increase in the amount of non-REM sleep and in the duration of non-REM sleep episodes in rats 

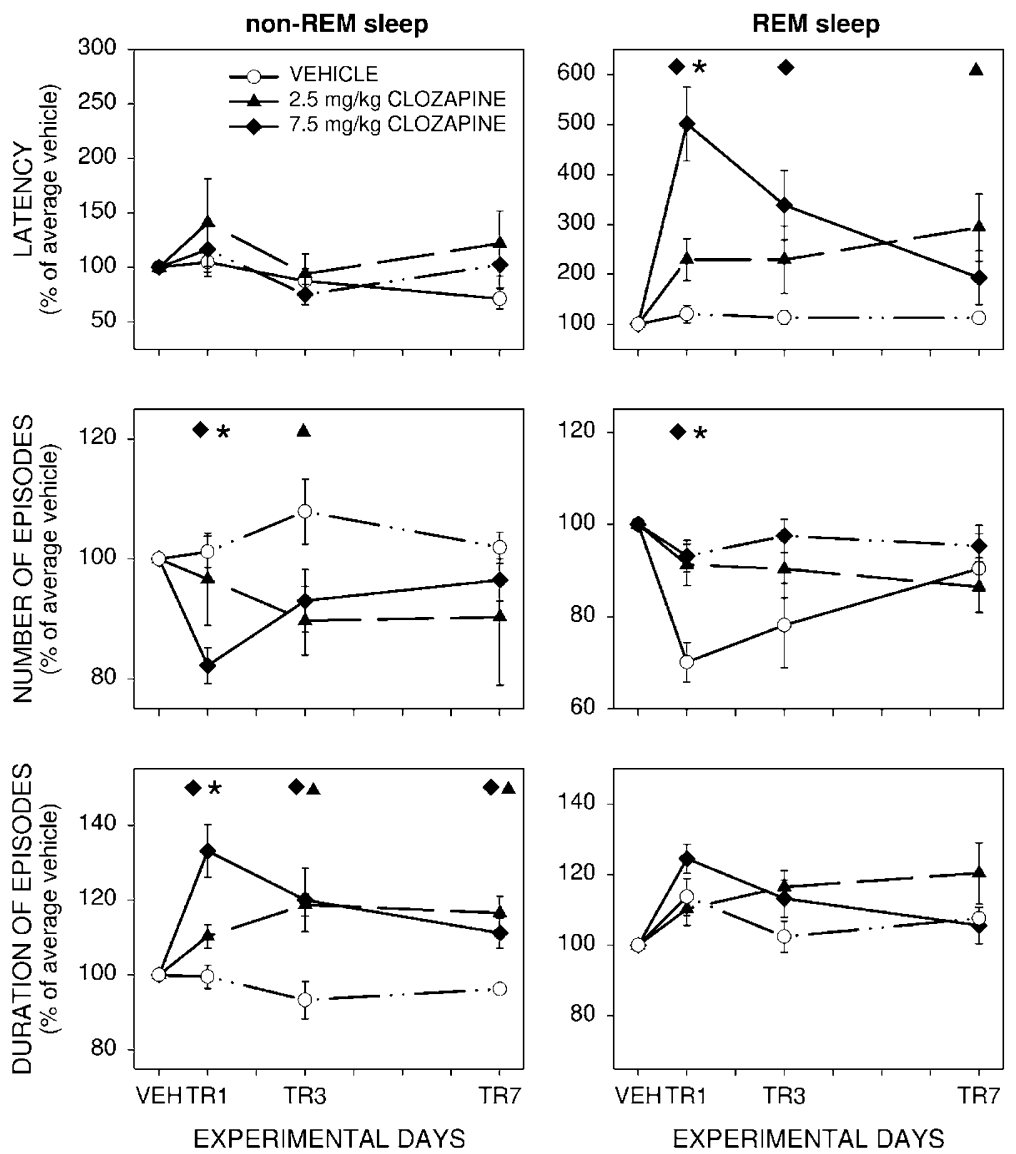

Figure 3 Latencies to non-REM and REM sleep, number and duration of non-REM and REM sleep episodes as percentage of the vehicle day after vehicle, 2.5 , and $7.5 \mathrm{mg} / \mathrm{kg}$ clozapine on experimental days (means $\pm \mathrm{SEM}, n=8 ; \mathrm{VEH}$ vehicle day, TRI first treatment day, TR3 third treatment day, TR7 seventh treatment day). Significant differences between the vehicle and a clozapine group are indicated by the clozapine group symbol and differences between the clozapine groups by an asterisk at the top of the plots ( $p \leqslant 0.05$, Tukey test).

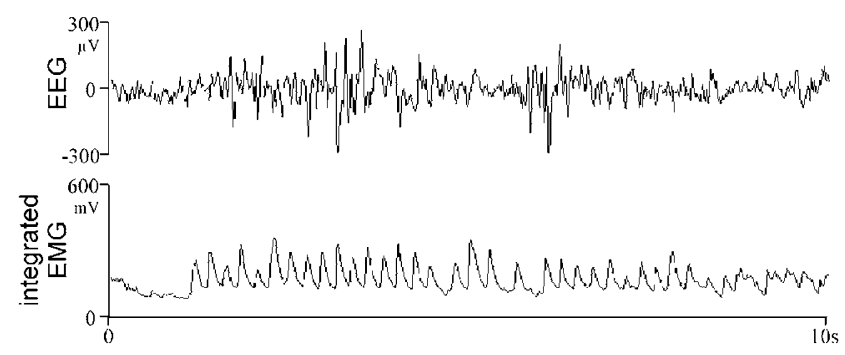

Figure 4 Typical clozapine-elicited EEG signals within wakefulness (upper plot EEG, lower plot integrated EMG).

was found throughout the experiment. Subtle signs of tolerance development were observed only for the clozapine-evoked reduction in the number of non-REM sleep episodes.

Upon acute administration the high dose of clozapine initially inhibited sleep in rats. A similar suppression has been observed in cats (Susic et al, 1975). We found that at the same time SWA in the EEG within non-REM sleep was attenuated, suggesting a decrease in sleep intensity. Remarkably, this short-lasting attenuation was not followed by rebound elevations. Tolerance towards these effects developed in the course of the experiment, since both the transient decrease in non-REM sleep as well as the attenuation of SWA had completely vanished on treatment day 7. Upon acute administration, the high dose of clozapine decreased the total amount of REM sleep, which was previously reported by Ongini et al (1993). The suppression of REM sleep was related to a prolonged REM sleep latency and a reduction of the number of REM sleep episodes. The findings suggest that the reduction of REM sleep is due to a suppression of mechanisms of REM sleep initiation. In humans, sleep-disturbing effects of clozapine, such as a supression of SWS and REM sleep, are known to occur during clozapine-induced fever (HinzeSelch et al, 1995).

However, in rats clozapine elicited a dose-dependent decrease in brain temperature, which is in line with previous studies measuring core body temperature after injection of clozapine (Maj et al, 1974; Menon et al, 1988; Salmi et al, 1994; Millan et al, 1995; Salmi and Ahlenius, 1996; Oerther and Ahlenius, 2000). In the present study we showed that this transient hypothermia was followed by a moderate, but long-lasting, dose-dependent elevation in brain temperature, beginning $7 \mathrm{~h}$ after clozapine administration. For both effects no signs of tolerance developed during subchronic treatment with clozapine. Possibly different mechanisms are responsible for the changes in temperature in humans and rats. 

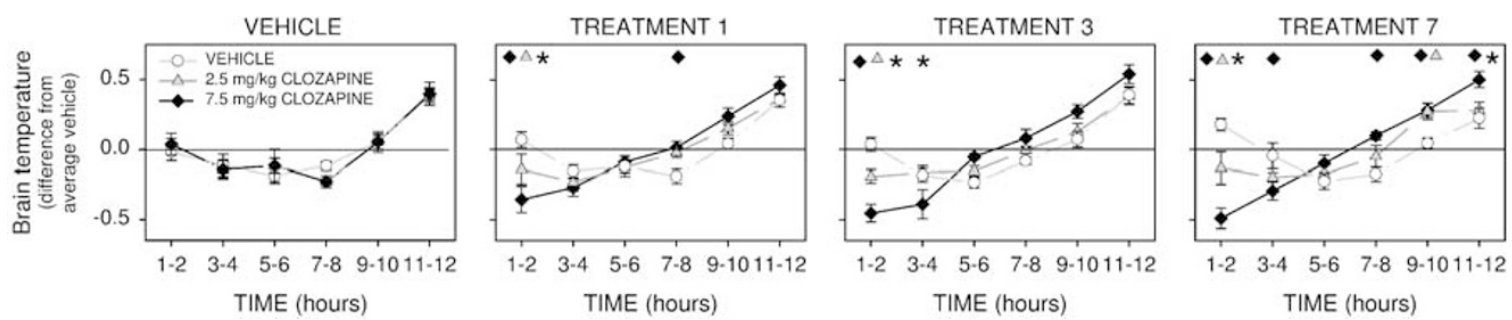

Figure 5 Time course of brain temperature after vehicle $(n=6), 2.5(n=6)$, and $7.5 \mathrm{mg} / \mathrm{kg}$ clozapine $(n=7)$ on experimental days. Values are expressed as deviation from 12-h vehicle value of an animal in ${ }^{\circ} \mathrm{C}$ (means $\pm \mathrm{SEM}$ ). Results of ANOVA follow group by time: Vehicle day: $\mathrm{F}(\mathrm{I0,80})=0.8, p \leqslant 0.6$; treatment day I: $F(\mid 0,80)=3.6, p \leqslant 0.00 I$; treatment day 3: $F(I 0,80)=4.8, p \leqslant 0.00 I$; treatment day $7: F(I 0,80)=7.8, p \leqslant 0.00 \mid$. Significant differences between the vehicle and a clozapine group are indicated by the clozapine group symbol and differences between the clozapine groups by an asterisk at the top of the plots ( $p \leqslant 0.05$, Tukey test).

Furthermore, we observed alterations in EEG signals within wakefulness in clozapine-treated rats. Interestingly, no signs of tolerance were found for $2.5 \mathrm{mg} / \mathrm{kg}$ clozapine, whereas in the group treated with $7.5 \mathrm{mg} / \mathrm{kg}$ clozapine these characteristic EEG signals disappeared in the course of the experiment. In humans, EEG abnormalities during wakefulness such as a slowing of theta and delta or even the occurrence of epileptic seizures are well documented (Günther et al, 1993; Welch et al, 1994; Freudenreich et al, 1997; Silvestri et al, 1998; Schuld et al, 2000; Centorrino et al, 2002). The factors contributing to the alterations in the EEG signals in humans as well as rats are still obscure.

In summary, the effects of clozapine on sleep-wake behavior and EEG signals, but not on body temperature, are very similar in rats and humans. Thus, the rat is a suitable model for investigating the interactions between clozapine and sleep-wake behavior and provides a new perspective for further research about the unique properties of clozapine.

The immune system, in particular the TNF cytokine system, has been suggested to contribute to the atypical properties of clozapine in schizophrenic patients (Pollmächer et al, 2000). Increased systemic levels of TNF- $\alpha$ in humans treated with clozapine are well in line with the suggestion that this cytokine contributes to side effects, such as fever, agranulocytosis, and others (Pollmächer et al, 2001). Preliminary data of our own suggest that high doses of clozapine increases TNF- $\alpha$ concentrations in brain tissue, especially in the frontal cortex of rats (unpublished data). Further studies should clarify whether TNF- $\alpha$ contributes to the effects of clozapine on the central nervous system, and if so whether this is a direct action or mediated via effects on classical neurotransmitters involved in sleep regulation such as histamine (Alvarez et al, 1994) or serotonine (Yamada et al, 2000).

\section{ACKNOWLEDGEMENTS}

We thank Arnold Höhne for technical assistance and Novartis Pharma for providing the ingredients and the recipe of the solvent of the Leponex ${ }^{\circledR}$ solution for injections. The study was supported by the Volkswagen Stiftung (Grant I/65163).

\section{REFERENCES}

Alvarez XA, Franco A, Fernandez-Novoa L, Cacabelos R (1994). Effects of neurotoxic lesions in histaminergic neurons on brain tumor necrosis factor levels. Agents Actions 41: C70-C72.

Baldessarini RJ, Frankenburg FR (1991). Clozapine, a novel antipsychotic agent. $N$ Engl J Med 324: 746-754.

Centorrino F, Price BH, Tuttle M, Bahk WM, Hennen J, Albert MJ et al (2002). EEG abnormalities during treatment with typical and atypical antipsychotics. Am J Psychiatry 159: 109-115.

Freudenreich O, Weiner RD, McEvoy JP (1997). Clozapine-induced electroencephalogram changes as a function of clozapine serum levels. Biol Psychiatry 42: 132-137.

Günther W, Baghai T, Naber D, Spatz R, Hippius H (1993). EEG alterations and seizures during treatment with clozapine. A retrospective study of 283 patients. Pharmacopsychiatry 26: 69-74.

Hinze-Selch D, Deuschle M, Weber B, Heuser I, Pollmächer T (2000). Effects of coadministration of clozapine and fluvoxamine versus clozapine monotherapy on blood cell counts, plasma levels of cytokines and body weight. Psychopharmacology 149: 163-169.

Hinze-Selch D, Mullington J, Orth A, Lauer CJ, Pollmächer T (1997). Effects of clozapine on sleep: a longitudinal study. Biol Psychiatry 42: 260-266.

Hinze-Selch D, Mullington J, Pollmacher T (1995). Sleep during clozapine-induced fever in a schizophrenic patient. Biol Psychiatry 38: 690-693.

Krueger JM, Obal FJ, Fang J, Kubota T, Taishi P (2001). The role of cytokines in physiological sleep regulation. Ann NY Acad Sci 933: 211-221.

Lancel M, Crönlein J, Müller-Preuss P, Holsboer F (1995). Lipopolysaccharide increases EEG delta activity within nonREM sleep and disrupts sleep continuity in rats. Am J Physiol 37: R1310-R1318.

Lancel M, Faulhaber J, Holsboer F, Rupprecht R (1996). Progesterone induces changes in sleep comparable to those of agonistic GABAA receptor modulators. Am J Physiol 271: E763-72.

Lee JH, Woo JI, Meltzer HY (2001). Effects of clozapine on sleep measures and sleep-associated changes in growth hormone and cortisol in patients with schizophrenia. Psychiatry Res 103: 157-166.

Lin JS, Sakai K, Jouvet M (1994). Hypothalamo-preoptic histaminergic projections in sleep-wake control in the cat. Eur $J$ Neurosci 6: 618-625.

Maj J, Sowinska H, Baran L, Palider W (1974). The central action of clozapine. Pol J Pharmacol Pharm 26: 425.

Menon MK, Gordon LI, Fitten J (1988). Interaction between clozapine and a lipophilic alpha 1-adrenergic agonist. Life Sci 43: 1791-1804. 
Millan MJ, Audinot V, Melon C, Newman-Tancredi A (1995). Evidence that dopamine D3 receptors participate in clozapineinduced hypothermia. Eur J Pharmacol 280: 225-229.

Neckelmann D, Ursin R (1993). Sleep stages and EEG power spectrum in relation to acoustical stimulus arousal threshold in the rat. Psychopharmacology 93: 226-229.

Oerther S, Ahlenius S (2000). Atypical antipsychotics and dopamine $\mathrm{D}(1)$ receptor agonism: an in vivo experimental study using core temperature measurements in the rat. $J$ Pharmacol Exp Ther 292: 731-736.

Ongini E, Bonizzoni E, Ferri N, Milani S, Trampus M (1993). Differential effects of dopamin D-1 and D-2 receptor antagonist antipsychotics on sleep-wake patterns in the rat. J Pharmacol Exp Ther 266: 726-731.

Pollmächer T (2002). Treatment of schizophrenia. In: Smelser $\mathrm{NJ}$, Baltes $\mathrm{PB}$ (eds). International Encyclopedia of the Social and Behavioral Sciences. Pergamon: Kidlington. pp 13546-13552.

Pollmächer T, Haack M, Schuld A, Kraus T, Hinze-Selch D (2000). Effects of antipsychotic drugs on cytokine networks. J Psychiatr Res 34: 369-382.

Pollmächer T, Hinze-Selch D, Mullington J (1996). Effects of clozapine on plasma cytokine and soluble cytokine receptor levels. J Clin Psychopharmacol 16: 403-409.

Pollmächer T, Schuld A, Kraus T, Haack M, Hinze-Selch D (2001). Zur klinischen Relevanz der Wirkung von Clozapin auf die Freisetzung von Zytokinen und löslichen Zytokinrezeptoren. Fortschr Neurol Psychiat 69: 65-74.

Salmi P, Ahlenius S (1996). Further evidence for clozapine as a dopamine D1 receptor agonist. Eur J Pharmacol 307: 27-31.

Salmi P, Karlsson T, Ahlenius S (1994). Antagonism by SCH 23390 of clozapine-induced hypothermia in the rat. Eur J Pharmacol 253: 67-73.

Schuld A, Kuhn M, Haack M, Kraus T, Hinze-Selch D, Lechner C, Pollmacher T (2000). A comparison of the effects of clozapine and olanzapine on the EEG in patients with schizophrenia. Pharmacopsychiatry 33: 109-111.
Silvestri RC, Bromfield EB, Khoshbin S (1998). Clozapine-induced seizures and EEG abnormalities in ambulatory psychiatric patients. Ann Pharmacother 32: 1147-1151.

Spierings ELH, Dzoljic MR, Godschalk M (1977). Effects of clozapine on the sleep patterns in the rat. Pharmacology 15: 551-556.

Stutzmann JM, Eon B, Lucas M, Blanchard JC, Laduron PM (1992). RP 62203, a 5-hydroxytryptamine2 antagonist, enhances deep NREM sleep in rats. Sleep 15: 119-124.

Susic V, Kovacevic R, Momirov D (1975). Changes in sleep waking cycle produced by clozapine. In: Levin P, Koella WP (eds). Sleep. Instinct, Neurophysiology, Endocrinology, Episodes, Dreams, Epilepsy and intracranial Pathology, Proceedings of the Second European Congress, Rome, Italy, April 8-11, 1974. XI+525. Illus P, Karger S (eds). Basel, Switzerland; New York, NY, USA, ISBN 3-8055-2069-7. pp 311-315.

Touyz SW, Beumont PJV, Saayman GS, Zabow T (1977). A psychophysiological investigation of the short-term effects of clozapine upon sleep parameters of normal young adults. Biol Psychiatry 12: 801-822.

Vergnes M, Marescaux C, Micheletti G, Reis J, Depaulis A, Rumbach L, Warter JM (1982). Spontaneous paroxysmal electroclinical patterns in rat: a model of generalized nonconvulsive epilepsy. Neurosci Lett 33: 97-101.

Welch J, Manschreck T, Redmond D (1994). Clozapine-induced seizures and EEG changes. J Neuropsychiatry Clin Neurosci 6: 250-256.

Wetter TC, Lauer CJ, Gillich G, Pollmächer T (1996). The electroencephalographic sleep pattern in schizophrenic patients treated with clozapine or classical antipsychotic drugs. $J$ Psychiatr Res 30: 411-419.

Wilkinson LOL, Dourish CT (1991). Serotonin and animal behaviour. In: Peroutka SJ (ed) Serotonin Receptor Subtypes: Basic and Clinical Aspects. Wiley-Liss: New York. pp 147-210.

Yamada K, Iida R, Miyamoto Y, Saito K, Sekikawa K, Seishima M, Nabeshima T (2000). Neurobehavioral alterations in mice with a targeted deletion of the tumor necrosis factor-alpha gene: implications for emotional behavior. J Neuroimmunol 111: 131-138. 